Check for updates

Cite this: RSC Adv., 2017, 7, 44340

Received 16th July 2017

Accepted 25th August 2017

DOI: 10.1039/c7ra07833a

rsc.li/rsc-advances

\section{Restricted diffusion of model sulfides over a NiMo/ BK catalyst under hydrodesulfurization reaction conditions $\dagger$}

\author{
Huadong Wu, ab Aijun Duan, (D) $\ddagger^{* b}$ Zhen Zhao, (D) *b Chunming Xu, ${ }^{\text {b } G u i y u a n ~ J i a n g, ~(D) ~}$ \\ Jian Liu, (DD ${ }^{\mathrm{b}}$ Yuechang Wei, ${ }^{\mathrm{b}}$ Jianmei Li, ${ }^{\mathrm{b}}$ Kebin $\mathrm{Chi}^{\mathrm{c}}$ and Jia Guo ${ }^{\mathrm{a}}$
}

Micro-mesoporous composite Beta-KIT-6 (BK) material with cubic la $\overline{3} d$ mesoporous structure was synthesized, and then a NiMo/BK hydrodesulfurization (HDS) catalyst was prepared using BK as a support. Four kinds of model sulfides with different structures and molecular sizes, including thiophene, benzothiophene, dibenzothiophene, and 4,6-dimethyldibenzothiophene, were chosen as the reactant probe molecules. The intra-particle diffusion effects on HDS of these four different model sulfides were investigated systematically over the novel NiMo/BK micro-mesoporous-supported catalyst under HDS reaction conditions. The changing rules of the catalyst effective factor $(\eta)$ and effective diffusion coefficient $\left(D_{\mathrm{e}}\right)$ of model sulfides were investigated. The results showed that the $\eta$ values of $\mathrm{NiMo} / \mathrm{BK}$ catalyst in the HDS of different reactant molecules are higher than those of the traditional $\mathrm{NiMo} / \mathrm{Al}_{2} \mathrm{O}_{3}$ owing to excellent mass transfer ability of the well-ordered NiMo/BK catalyst, and the $D_{\mathrm{e}}$ values decreased with the increasing molecular sizes of model sulfur-containing compounds. The relationship of effective diffusion coefficient $\left(D_{e}\right)$ with molecule diameter to pore diameter ratio $(\lambda)$ was further determined. Restrictive factors were correlated by $F(\lambda)=(1-\lambda)^{3.15}$ for NiMo/BK and $F(\lambda)=$ $(1-\lambda)^{3.67}$ for $\mathrm{NiMo} / \mathrm{Al}_{2} \mathrm{O}_{3}$ catalyst, indicating that large pore size is beneficial to the diffusion of macromolecular reactants.

\section{Introduction}

In the past decades, an urgent problem facing up with the refineries is the production of low sulfur diesel to improve the fuel quality and minimize air pollution caused by combustion. Currently, hydrodesulfurization (HDS) is widely used. For the purposes of meeting the requirement of ultra deep desulfurization, it is necessary to remove almost all of the sulfides, including 4,6-dimethyldibenzothiophene (4,6-DMDBT) which is very difficult to be removed. Several approaches have been adopted to develop HDS catalysts and many researchers have focused on the design of novel HDS support materials. ${ }^{1,2}$

Mesoporous supports, like SBA-15 (ref. 3) and KIT- $6,{ }^{4}$ have been developed because of their wide pore channels which can reduce diffusion resistance for reactant molecules. ${ }^{5,6}$ Schacht $^{7}$

${ }^{a}$ Key Laboratory of Green Chemical Process, Wuhan Institute of Technology, Ministry of Education, Hubei Key Laboratory of Novel Chemical Reactor and Green Chemical Technology, Wuhan 430073, P. R. China

${ }^{b}$ State Key Laboratory of Heavy Oil Processing, China University of Petroleum, Beijing, P. R. China. E-mail: zhenzhao@cup.edu.cn; Fax: +86-10-69724728; Tel: +86-1089731586

'Petrochemical Research Institute, PetroChina Company Limited, Beijing, P. R. China $\dagger$ Electronic supplementary information (ESI) available. See DOI: 10.1039/c7ra07833a

$\$$ This author has equal contribution as the first author. found that the mesoporous support with suitable textural and mechanical properties was conducive to the enhancement of HDS activity. Non-noble metals such as $\mathrm{Co}, \mathrm{Mo}, \mathrm{Ni}$, and $\mathrm{W}$ are the active sites for hydrogenation in refinery process. ${ }^{8}$ Soni et al..$^{9}$ reported that CoMo/KIT-6 catalyst had higher activity in thiophene HDS than CoMo/SBA- 15 and $\mathrm{CoMo} / \mathrm{Al}_{2} \mathrm{O}_{3}$ catalysts because of well-ordered Ia3d mesostructure of KIT-6. However, pure mesoporous materials are devoid of Brönsted acid sites, ${ }^{10}$ which are significant for the acid-catalyzed reactions, especially for the HDS of highly refractory sulfides. ${ }^{11}$ Therefore, for the purpose to improve the acidity of different supports, micromesoporous composite materials have been synthesized and these materials were applied in different catalytic processes in recent years. ${ }^{12,13}$ Zeng et al. ${ }^{14}$ synthesized Beta-MCM-41 as a support to prepare NiW/Beta-MCM-41 catalyst, the Beta-MCM41-supported catalyst exhibited higher HDS activity than NiW/ $\mathrm{Al}_{2} \mathrm{O}_{3}$. In our previous works, Zhang et al. ${ }^{15,16}$ synthesized BetaSBA-15 and Beta-KIT-6 micro-mesoporous composite materials, which exhibited higher activities in DBT HDS. Furthermore, Beta-KIT- 6 possesses a larger pore $(6.5 \mathrm{~nm})$ cubic $I a \overline{3} d$ mesoporous structure than Beta-SBA-15 which is favorable for enhancing the mass transfer.

Although the micro-mesoporous material with open channels could eliminate the diffusion resistance to some extent, the intra-particle diffusion resistance still exists under the HDS 
reaction conditions. Furthermore, the intra-particle diffusion effect depends on operating conditions and the molecular sizes of sulfides. This issue is very important for deep understanding of HDS mechanism and process, but it has not been adequately and quantitatively illustrated in the open HDS literature. Although many HDS research works have been carried out separately with either full-size commercial catalysts ${ }^{17-19}$ or crushed catalyst particles, ${ }^{\mathbf{2 0}}$ especially there is no open report on the intra-particle diffusion of novel micro-mesoporous material-supported catalysts to our best knowledge.

In this study, Beta/KIT-6 composite material was prepared based on our previous work, and NiMo/BK catalyst was prepared using BK as a support and NiMo as active metals. In order to further investigate the hindered diffusion process of macromolecular sulfides in the pore channels of NiMo/BK catalyst, the hydrodesulfurization performance of different model sulfides (including thiophene, benzothiophene, dibenzothiophene, and 4,6-dimethyldibenzothiophene) were studied. The relationship of the catalyst effective factor $(\eta)$ and the effective diffusion coefficient $\left(D_{\mathrm{e}}\right)$ of the sulfur-containing model compounds with different structures and molecular sizes under different HDS reaction conditions were investigated systematically.

\section{Experimental}

\subsection{Synthesis of Beta/KIT-6 and NiMo catalysts}

Beta/KIT-6 (BK) was synthesized by a two-step crystallizaion method according to our previous work. ${ }^{\mathbf{1 6}} \mathrm{A}$ zeolite seed crystal was prepared through mixing $0.76 \mathrm{~g} \mathrm{NaAlO}, 0.19 \mathrm{~g} \mathrm{NaOH}$, $21.43 \mathrm{~g}$ tetraethylorthosilicate (TEOS), and $29.45 \mathrm{~g}$ TEAOH aqueous solution with mass fraction of $25 \%$. Then the obtained solution was stirred for $4 \mathrm{~h}$ and moved to a crystallization kettle for $20 \mathrm{~h}$ at $140{ }^{\circ} \mathrm{C}$ to obtain Beta zeolite seed crystals. $2 \mathrm{~g}$ Pluronic P123 $\left(\mathrm{EO}_{20} \mathrm{PO}_{70} \mathrm{EO}_{20}\right)$ was added in $49 \mathrm{~g} \mathrm{H} \mathrm{H}_{2} \mathrm{O}$ with $27 \mathrm{~g} \mathrm{HCl}$ of $2 \mathrm{~mol} \mathrm{~L}^{-1}$ at about $40{ }^{\circ} \mathrm{C}$, after that, $2.92 \mathrm{~g}$ of $n$-butanol was added $1 \mathrm{~h}$ later. Finally, $4.8 \mathrm{~g}$ tetraethylorthosilicate and $7.9 \mathrm{~g}$ zeolite seed obtained before were added dropwisely, the mixture solution was transferred to an crystallization kettle at $100{ }^{\circ} \mathrm{C}$ after stirred for $24 \mathrm{~h}$. The BK micro-mesoporous material was obtained after the processes of filtration, drying, and calcination.

The preparation method of the NiMo/BK catalyst adopted an ultrasonic incipient-wetness impregnation technique. Subsequently, all the catalysts were dried and calcined at $550{ }^{\circ} \mathrm{C}$ for $6 \mathrm{~h} . \mathrm{MoO}_{3}$ and $\mathrm{NiO}$ loading amounts were $10 \mathrm{wt} \%$, and $3.5 \mathrm{wt} \%$, respectively.

\subsection{Characterization}

X-ray diffraction (XRD) patterns were taken on a Rigaku RINT D/ Max-2500 powder diffraction system (40 kV, $50 \mathrm{~mA})$. FTIR spectra were recorded with a FTS-3000 spectrophotometer (American Digilab Company). Transmission electron microscopy (TEM) photos were taken on a Philips Tecnai G2 F20 transmission electron microscope. $\mathrm{N}_{2}$ adsorption and desorption were characterized using an automated gas adsorptiondesorption analyzer (Quantachrome Autosorb-iQ, USA).

\subsection{HDS reaction}

A fixed-bed reactor was used to evaluate the HDS activities of different catalysts using thiophene, benzothiophene, dibenzothiophene, and 4,6-DMDBT as reactants, loading $0.5 \mathrm{~g}$ catalyst mixed with $5 \mathrm{~g}$ silica sand in each HDS test. The concentration of liquid feed was $3310 \mathrm{ppm}$ 4,6-DMDBT in cyclohexane. The HDS reaction parameters were $280-340{ }^{\circ} \mathrm{C}, 3.0-6.0 \mathrm{MPa}, \mathrm{H}_{2} / \mathrm{Oil}$ ratio of $500-800 \mathrm{~mL} \mathrm{~mL} \mathrm{~m}^{-1}$, and liquid hourly space velocity (LHSV) of 2.0-200 $\mathrm{h}^{-1}$. Sulfur contents were analyzed by a fluorescence sulfur analyzer.

\section{Results and discussion}

\subsection{Characterization of the supports and catalysts}

3.1.1 XRD results of the BK support. XRD pattern of the BK material shows well-resolved peak at $2 \theta=0.88^{\circ}$, a shoulder peak at $2 \theta=0.88^{\circ}$ for (220) crystal plane, and a series peaks between $1.6^{\circ}$ and $2^{\circ}$ as same as that of pure KIT- 6 silica (Fig. S1 in ESI $\dagger$ ), implying that the synthesized BK support possesses a similar structure to the cubic $I a \overline{3} d$ mesoporous material of KIT- $6 .^{21}$

3.1.2 FTIR results of the supports. The FTIR spectra of BK support and Beta zeolite are shown in Fig. S2. $\dagger$ BK exhibits vibration bands at 520,570,810, 950, and $1030 \mathrm{~cm}^{-1}$. The wave number at $810 \mathrm{~cm}^{-1}$ is owing to symmetric vibration of $\mathrm{Si}-\mathrm{O}-\mathrm{Si}$ group, the wave number at $1030 \mathrm{~cm}^{-1}$ is owing to $\mathrm{Si}-\mathrm{O}-\mathrm{Si}$ asymmetric vibration. The wave number at $950 \mathrm{~cm}^{-1}$ is attributed to defective $\mathrm{Si}-\mathrm{OH}$ vibration. ${ }^{22}$ Two wave numbers at 520 and $570 \mathrm{~cm}^{-1}$ are the typical vibration peaks of six- or fivemember ring of $\mathrm{Si}-\mathrm{O}-\mathrm{Si}$ or $\mathrm{Si}-\mathrm{O}-\mathrm{Al}$ in primary building units of zeolite. ${ }^{23}$ The two bands existed in both BK and Beta, which indicates that primary building units of Beta zeolite exists in the BK material and the BK micro/mesoporous material is built by primary units of zeolite Beta.

3.1.3 TEM images of the BK material. The central domain are aligned along with the [111] and [100] directions of BK support as shown in Fig. S3(A) and S3(B), $\dagger$ respectively. The TEM images exhibit well-ordered arrangements of mesopore channels, which are similar to those of reported KIT-6 materials previously. ${ }^{4}$ In addition, large pore channels of BK are visible obviously in the TEM photos. The images further confirm that the BK composite possesses the $I a \overline{3} d$ cubic structure. These observations are in accordance with the results of XRD and FTIR.

3.1.4 $\mathbf{N}_{2}$ adsorption-desorption. As shown in Fig. 1A, the BK support and NiMo/BK catalyst exhibit type IV isotherms with a clear $\mathrm{H} 1$ type hysteresis loop, which is the representative curve characteristic of ordered mesoporous. Narrow mesoporous size distributions are obtained on them as presented in Fig. 1B. Moreover, a steep increase at $p / p_{0}<0.02$ of the BK support and $\mathrm{NiMo} / \mathrm{BK}$ catalyst can be interpreted as microporous filling, the other steep increase at $0.5<p / p_{0}<0.65$ is caused by capillary condensation on mesospores. The $\mathrm{Al}_{2} \mathrm{O}_{3}$ support and NiMo/ $\mathrm{Al}_{2} \mathrm{O}_{3}$ show $\mathrm{H} 4$ hysteresis loop with a wide pore size distribution. ${ }^{16}$ The BK composite support exhibits higher surface areas $\left(750 \mathrm{~m}^{2} \mathrm{~g}^{-1}\right)$ and larger pore volumes $\left(0.84 \mathrm{~m}^{2} \mathrm{~g}^{-1}\right)$ than the commercial $\mathrm{Al}_{2} \mathrm{O}_{3}$ support (Table 1). Moreover, BK shows a relatively larger micropore volume $\left(0.15 \mathrm{~m}^{3} \mathrm{~g}^{-1}\right)$ than $\mathrm{Al}_{2} \mathrm{O}_{3}$. 

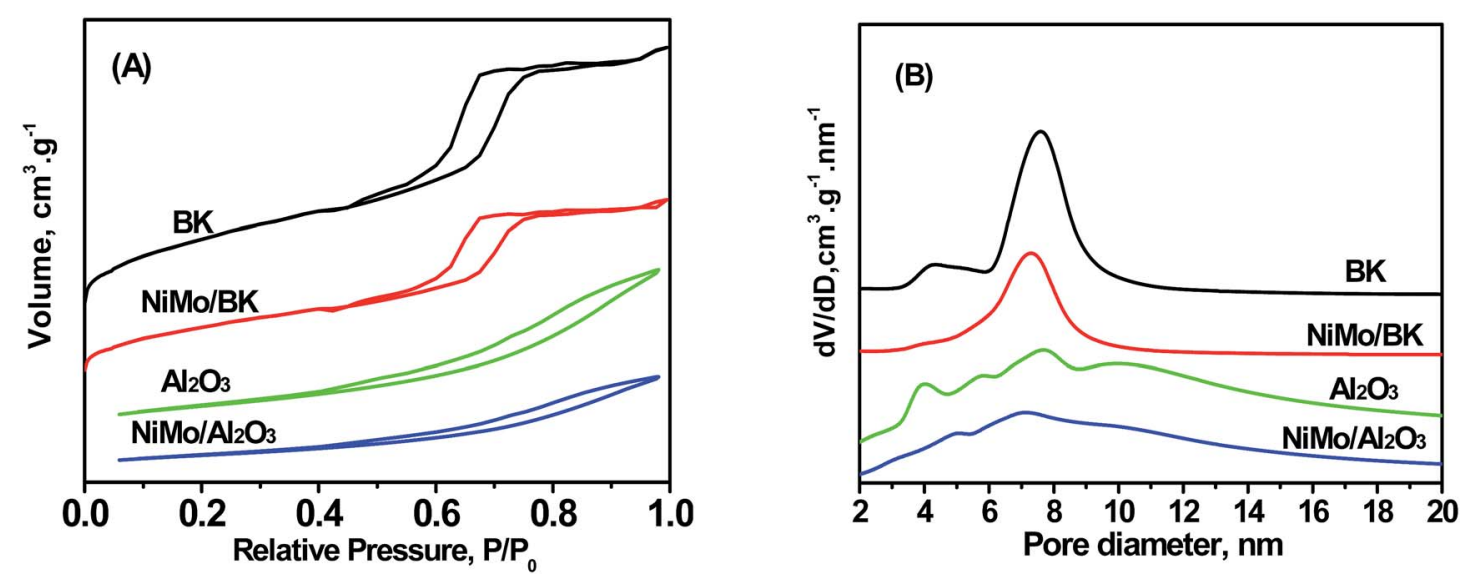

Fig. $1 \mathrm{~N}_{2}$ adsorption-desorption isotherms (A) and BJH pore diameter distributions (B) patterns of the catalysts.

This is due to the assembly of six- or five-member rings of $\mathrm{T}-\mathrm{O}-\mathrm{T}(\mathrm{T}=\mathrm{Si}$ or $\mathrm{Al})$ of zeolite Beta into the $\mathrm{BK}$ mesoporous framework, which is beneficial to improving the stability and increasing pore volume. After the impregnation of metals, the $\mathrm{NiMo/BK}$ shows higher surface area and pore volume than the traditional $\mathrm{NiMo} / \mathrm{Al}_{2} \mathrm{O}_{3}$ catalyst.

\subsection{Properties of the catalyst pellets}

In order to investigate the pore size distribution of the catalyst pellets, the powder catalysts were squashed, then sieved to obtain a series of catalyst pellets with different particle sizes of 20-40, 40-60, 60-80, and 80-100 meshes. The pore size distribution becomes more concentrated with the decreasing of particle size as shown in Fig. 2. The average pore sizes and bulk densities change marginally after crushing. The pore size distribution becomes more concentrated with the decreasing of particle size. The average pore diameter of different NiMo/BK catalyst pellets ranges from 7.2 to $7.4 \mathrm{~nm}$. The typical properties of the catalyst pellets are shown in Table 2, which exhibits that the bulk density of different NiMo/BK catalyst pellets ranges from 375 to $385 \mathrm{~kg} \mathrm{~m}^{-3}$. These pellets were used in the following experiments to eliminate the internal diffusion.

\subsection{Effectiveness factor $(\eta)$ and effective diffusion coefficient $\left(D_{\mathrm{e}}\right)$}

3.3.1 Elimination of external diffusion. External diffusion plays an important role in HDS results, Mears criterion is usually used to judge whether the external diffusion effects can be ignored. ${ }^{24}$
Mears criterion:

$$
\frac{-r_{\mathrm{apparent}} \rho_{\mathrm{b}} R n}{k_{\mathrm{c}} C_{\mathrm{Ab}}}<0.15
$$

where $\rho_{\mathrm{b}}$ is catalyst bulk density $\left(\mathrm{kg} \mathrm{m}^{-3}\right), R$ represents catalyst particle radius (m), $n$ means reaction order, and $C_{\mathrm{Ab}}$ is the bulk concentration $\left(\mathrm{kmol} \mathrm{m}^{-3}\right) . k_{\mathrm{c}}$ is mass transfer coefficient. ${ }^{25}$ Substituting these parameters into the above equation of Mears criterion, inequality (1) was satisfied in the experiments, indicating that the external diffusion was eliminated and can be neglected in this work.

3.3.2 Removal of internal diffusion. With the purpose of investigating the influence of internal diffusion on HDS process, $\mathrm{NiMo} / \mathrm{BK}$ and $\mathrm{NiMo} / \mathrm{Al}_{2} \mathrm{O}_{3}$ catalysts with different pellet sizes were evaluated in HDS under the conditions of $300{ }^{\circ} \mathrm{C}$, $4 \mathrm{MPa}, 20 \mathrm{~h}^{-1}$, and $\mathrm{H}_{2} /$ Oil ratio of 600 using 4,6-DMDBT as a model reactant. Fig. 3 demonstrates the desulfurization efficiencies over the two catalysts with different pellet sizes. The desulfurization efficiency decreases with the catalyst particle size increasing from 60 to 20 mesh, demonstrating that the internal diffusion effect in these catalyst pellets gradually decreased with the decreasing of pellet sizes. However, when pellet size is less than 60 meshes, there is no significant effect of the internal diffusion. Thus, it can be deduced from Fig. 3 that the effect of internal diffusion can be ignored if the pellet size is less than 60 meshes. ${ }^{26}$ Therefore, in the following experiments, the catalyst pellets were kept for $60-80$ meshes to analyze the intrinsic kinetic data and avoid stacking in the reactor densely.

Hydrodesulfurization of BT and 4,6-DMDBT was tested over 60-80 meshes catalysts to investigate the intrinsic HDS reaction

Table 1 Textural properties of the $\mathrm{BK}, \mathrm{Al}_{2} \mathrm{O}_{3}$ supports and $\mathrm{BK}$ - and $\mathrm{Al}_{2} \mathrm{O}_{3}$-supported NiMo catalysts

\begin{tabular}{|c|c|c|c|c|c|}
\hline Catalysts & $S_{\mathrm{BET}}{ }^{a}\left(\mathrm{~m}^{2} \mathrm{~g}^{-1}\right)$ & $V_{\mathrm{t}}^{b}\left(\mathrm{~m}^{2} \mathrm{~g}^{-1}\right)$ & $V_{\mathrm{mes}}{ }^{c}\left(\mathrm{~m}^{3} \mathrm{~g}^{-1}\right)$ & $V_{\mathrm{mic}}{ }^{d}\left(\mathrm{~m}^{3} \mathrm{~g}^{-1}\right)$ & $D_{\mathrm{BJH}}{ }^{c}(\mathrm{~nm})$ \\
\hline BK & 750 & 0.84 & 0.70 & 0.15 & 7.2 \\
\hline $\mathrm{Al}_{2} \mathrm{O}_{3}$ & 232 & 0.56 & 0.55 & 0.02 & 7.8 \\
\hline $\mathrm{NiMo} / \mathrm{Al}_{2} \mathrm{O}_{3}$ & 168 & 0.40 & 0.39 & 0.01 & 7.2 \\
\hline
\end{tabular}

${ }^{a}$ Calculated by the BET method. ${ }^{b}$ The total pore volume was obtained at a relative pressure of $0.98 .{ }^{c}$ Calculated using the BJH method.

${ }^{d}$ Calculated using the $t$-plot method. 


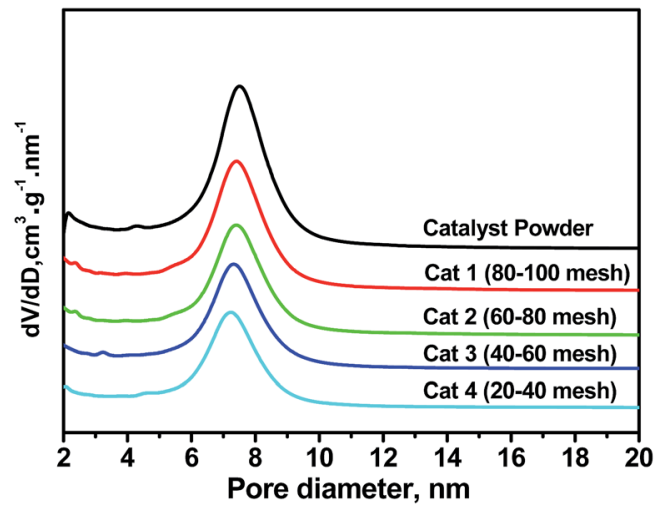

Fig. 2 BJH pore diameter distributions of $\mathrm{NiMo/BK}$ catalyst powder and pellets.

order of model sulfides. The HDS results obtained at different LHSVs $\left(300{ }^{\circ} \mathrm{C}, 4 \mathrm{MPa}\right.$, and $\mathrm{H}_{2} /$ Oil ratio of 600$)$ are shown in Fig. 4. The HDS conversion decreased dramatically with the increasing of LHSV over the two catalysts. The BT conversions were higher than those of 4,6-DMDBT at all LHSVs. The relevance between $\ln [1 /(1-X)]$ and $1 /$ LHSV is shown in Fig. 5 . Fitted straight lines were obtained based on the experimental data points in HDS of model sulfides of BT and 4,6-DMDBT, indicating that the HDS reaction of individual model sulfides follow pseudo-first order kinetic under the reaction conditions used in this research, which agrees with the literature. ${ }^{27,28}$

3.3.3 Factors that affect $\boldsymbol{\eta}$ and $D_{\mathrm{e}}$ in HDS reactions. Many researchers ${ }^{19,27,28}$ have recognized that HDS of a single reactant molecule follows first-order reaction model. The kinetic equation of a HDS reaction may be expressed as:

$$
\ln \frac{c_{0}}{c_{1}}=-\ln (1-X)=\ln \frac{1}{1-X}=\frac{k_{1}}{\mathrm{LHSV}}
$$

where $c_{0}$ is the sulphur content in feed, while $c_{1}$ is the sulphur content in product. $X$ is the percentage of sulphur removal and $k_{1}$ is the reaction rate constant $\left(\mathrm{h}^{-1}\right)$.

The catalyst effectiveness factors $(\eta)$ with particle size larger than 60 meshes can be calculated based on the following equation:

$$
\eta=\frac{k_{\text {apparent }}}{k_{\text {intrinsic }}}
$$

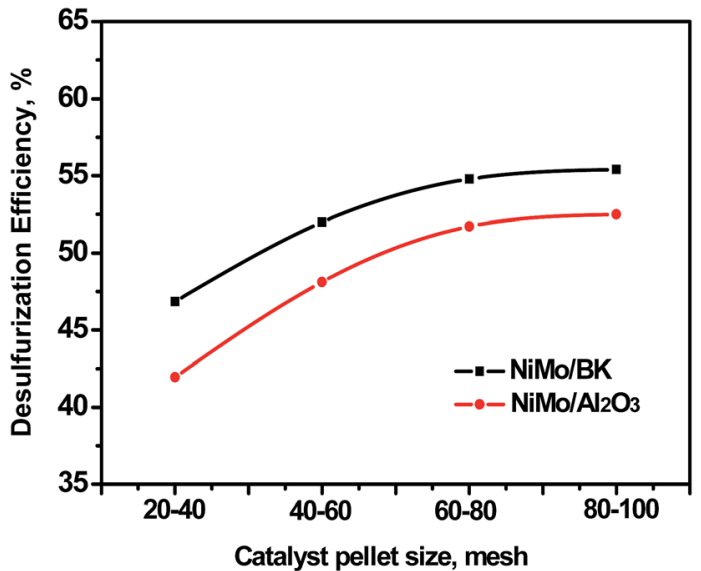

Fig. 3 Relationship between the desulfurization efficiency and the catalyst pellet size.

For spheres crushed catalysts,

$$
\begin{gathered}
\eta=\frac{3}{\Phi}\left(\frac{1}{\tanh \Phi}-\frac{1}{\Phi}\right) \\
\Phi=\frac{V_{\mathrm{p}}}{S_{\mathrm{p}}} \sqrt{k_{\text {intrinsic }} / D_{\mathrm{e}}}
\end{gathered}
$$

where $k_{\text {apparent }}$ is apparent reaction rate constant, while $k_{\text {intrinsic }}$ represents the intrinsic reaction rate constant; $\Phi$ is Thiele modulus; and $V_{\mathrm{p}}$ is the volume of the catalyst, $S_{\mathrm{p}}$ is the catalyst surface area. Based on the data obtained from different catalysts, the values of $k_{\text {intrinsic }}$ and $k_{\text {apparent }}$ could be calculated, and then the $\eta$ and $D_{\mathrm{e}}$ could also be determined. Thus, $\eta$ and $D_{\mathrm{e}}$ under different HDS reaction conditions could be calculated. Four typical sulfides, including thiophene, benzothiophene, dibenzothiophene, and 4,6-dimethyldibenzothiophene, were chosen as probe molecules to study the hindered diffusion processes of different sulfides. The molecular structures and sizes of these sulfides are shown in Table 3.

3.3.3.1 Temperature. The temperature influence was investigated at $4 \mathrm{MPa}, 20 \mathrm{~h}^{-1}$, and $\mathrm{H}_{2} / \mathrm{Oil}$ ratio of 600 . As shown in Fig. 6, the $\eta$ decreases notably and the $D_{\mathrm{e}}$ increases mildly along with the rising of reaction temperature. On the one hand, a significant increase in intrinsic reaction rate is achieved at higher temperature. On the other hand, mass transfer of

Table 2 Properties of the catalysts with different particle sizes

\begin{tabular}{llll}
\hline Catalysts & Bulk density $\left(\mathrm{kg} \mathrm{m}^{-3}\right)$ & Average pore diameter $(\mathrm{nm})$ & Range of particle size (mm) \\
\hline $\mathrm{NiMo} / \mathrm{Al}_{2} \mathrm{O}_{3}(20-40$ mesh) & 785 & 7.0 & $0.74-0.37$ \\
$\mathrm{NiMo} / \mathrm{Al}_{2} \mathrm{O}_{3}(40-60$ mesh) & 788 & 7.0 & $0.37-0.25$ \\
$\mathrm{NiMo} / \mathrm{Al}_{2} \mathrm{O}_{3}(60-80 \mathrm{mesh})$ & 792 & 7.1 & $0.25-0.19$ \\
$\mathrm{NiMo} / \mathrm{Al}_{2} \mathrm{O}_{3}(80-100 \mathrm{mesh})$ & 796 & 7.2 & $0.19-0.16$ \\
$\mathrm{NiMo} / \mathrm{BK}(20-40 \mathrm{mesh})$ & 375 & 7.2 & $0.74-0.37$ \\
$\mathrm{NiMo} / \mathrm{BK}(40-60 \mathrm{mesh})$ & 378 & 7.2 & $0.37-0.25$ \\
$\mathrm{NiMo} / \mathrm{BK}(60-80 \mathrm{mesh})$ & 382 & 7.3 & $0.25-0.19$ \\
$\mathrm{NiMo} / \mathrm{BK}(80-100 \mathrm{mesh})$ & 385 & 7.4 & $0.19-0.16$
\end{tabular}



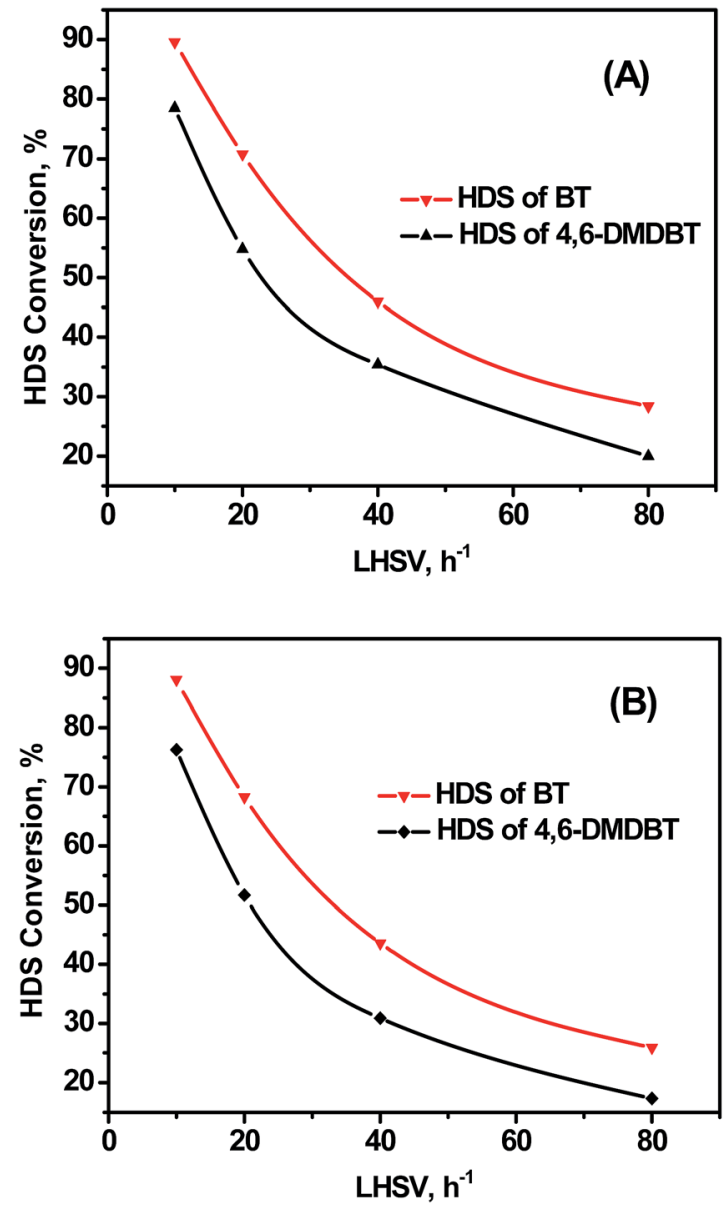

Fig. $4 \mathrm{HDS}$ results of $\mathrm{BT}$ and 4,6-DMDBT over $\mathrm{NiMo} / \mathrm{BK}(\mathrm{A})$ and $\mathrm{NiMo} /$ $\mathrm{Al}_{2} \mathrm{O}_{3}$ (B) catalysts at different LHSVs.

reactants in catalyst channel is improved at higher temperatures. Thus, smaller $\eta$ and larger $D_{\mathrm{e}}$ are obtained at higher temperatures as shown in Fig. 6. Furthermore, in the HDS of the same probe molecules (BT or 4,6-DMDBT), the $\eta$ over NiMo/BK is higher than that over $\mathrm{NiMo} / \mathrm{Al}_{2} \mathrm{O}_{3}$, and the $\eta$ of the two catalysts in the HDS of BT are higher than those in the HDS of 4,6-DMDBT (Fig. 6A). Likewise, the $D_{\mathrm{e}}$ in the HDS of BT is higher than that of 4,6-DMDBT (Fig. 6B), indicating that small reactant molecule (BT) suffered less restricted diffusion than 4,6DMDBT with large molecule size in HDS reaction. The $D_{\mathrm{e}}$ over $\mathrm{NiMo} / \mathrm{BK}$ catalyst in the HDS reaction are higher than that of $\mathrm{NiMo} / \mathrm{Al}_{2} \mathrm{O}_{3}$, indicating that the $\mathrm{NiMo} / \mathrm{BK}$ impose smaller diffusion resistance on the reactant molecules. This is attributed to the well-ordered mesostructure of BK with large pore channels, which is beneficial to diffusion of reactant.

3.3.3.2 Pressure. The pressure influence on HDS was investigated at $300{ }^{\circ} \mathrm{C}, 20 \mathrm{~h}^{-1}$, and $\mathrm{H}_{2} / \mathrm{Oil}$ of 600 . Fig. 7 shows the changing tendency of $\eta$ and $D_{\mathrm{e}}$ with the operation pressure. The $\eta$ decreases and $D_{\mathrm{e}}$ increases slightly as the pressure increases. At high pressures, the reactants concentration and hydrogen solubility increases which can decrease the viscosity of the liquid. Moreover, the concentration of hydrogen on catalyst surface increases because of high pressure, which results in an
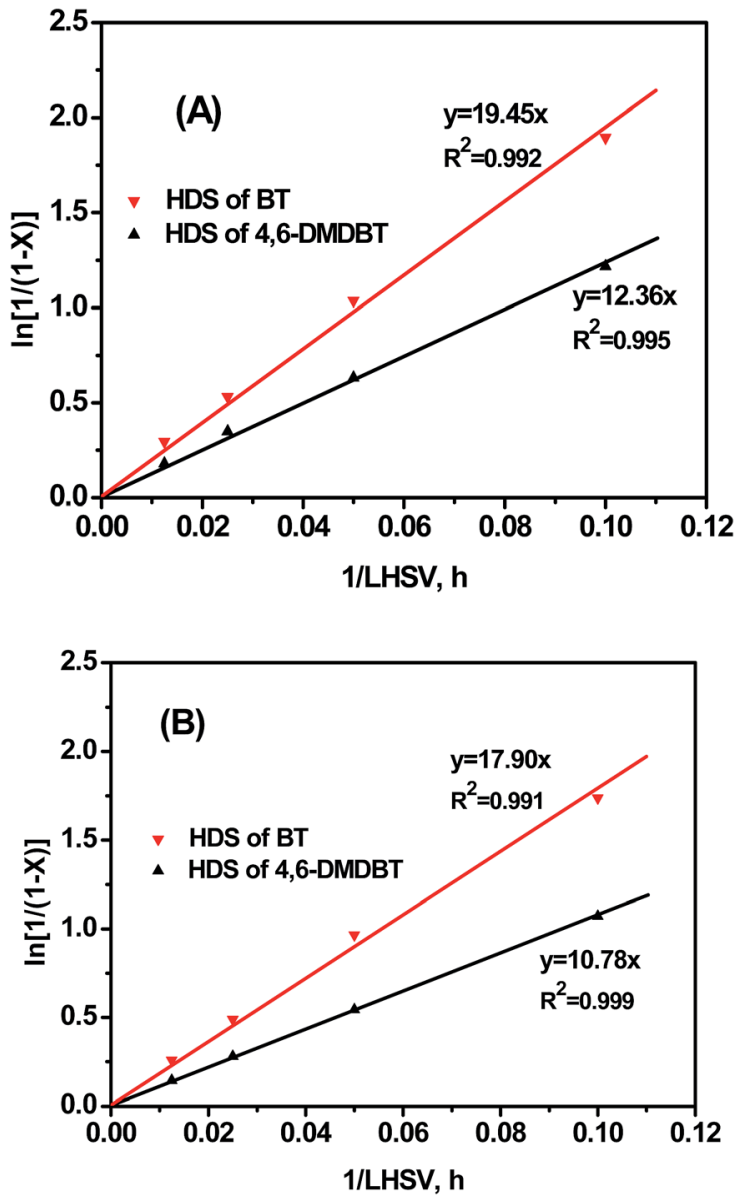

Fig. 5 Relationships between $\ln [1 /(1-X)]$ and 1/LHSV of NiMo/BK (A) and $\mathrm{NiMO} / \mathrm{Al}_{2} \mathrm{O}_{3}(\mathrm{~B})$ catalysts.

increasing of the intrinsic rate in the catalyst channel. Therefore, the $\eta$ decreases slightly as the pressure increases. Similarly, the $D_{\mathrm{e}}$ of BT and 4,6-DMDBT increases with the increasing of pressure. Most of all, the $\eta$ and $D_{\mathrm{e}}$ over NiMo/BK are both higher than those over NiMo/ $/ \mathrm{Al}_{2} \mathrm{O}_{3}$ in the HDS of two reactants (BT and 4,6-DMDBT) in the pressure range of 3-6 MPa, demonstrating the excellent diffusion ability of the well-ordered micro-mesoporous NiMo/BK catalyst.

3.3.3.3 $\mathrm{H}_{2} /$ Oil ratio. The influence of $\mathrm{H}_{2} / \mathrm{Oil}$ ratio was studied in the range of $500-800(\mathrm{v} / \mathrm{v})$ at $300^{\circ} \mathrm{C}, 4 \mathrm{MPa}, 20 \mathrm{~h}^{-1}$. As shown in Fig. 8, the changes of $\mathrm{H}_{2} / \mathrm{Oil}$ ratio result in the changes of hydrogen partial pressure when the total pressure remains constant. Thus, the intrinsic reaction rate was promoted and the $\eta$ decreases with the increasing of $\mathrm{H}_{2} / \mathrm{Oil}$ ratio. Meanwhile, $D_{\mathrm{e}}$ increases slightly since high hydrogen partial pressures could accelerate the diffusion behavior of the reactant in catalyst pore. Meanwhile, because of the superior mass transfer property of BK support, the $\eta$ and $D_{\mathrm{e}}$ over NiMo/BK catalyst are all higher than those over $\mathrm{NiMo} / \mathrm{Al}_{2} \mathrm{O}_{3}$ catalyst in the HDS of two probe reactants.

3.3.4 Effects of molecular sizes. The effect of molecular size on the HDS process were investigated by using different model sulfides with different mode sizes, such as 4,6-DMDBT, DBT, $\mathrm{BT}$, and T. Under fixed reaction conditions of $300{ }^{\circ} \mathrm{C}, 4 \mathrm{MPa}$, 
Table 3 Molecular structures and sizes of different model sulfides
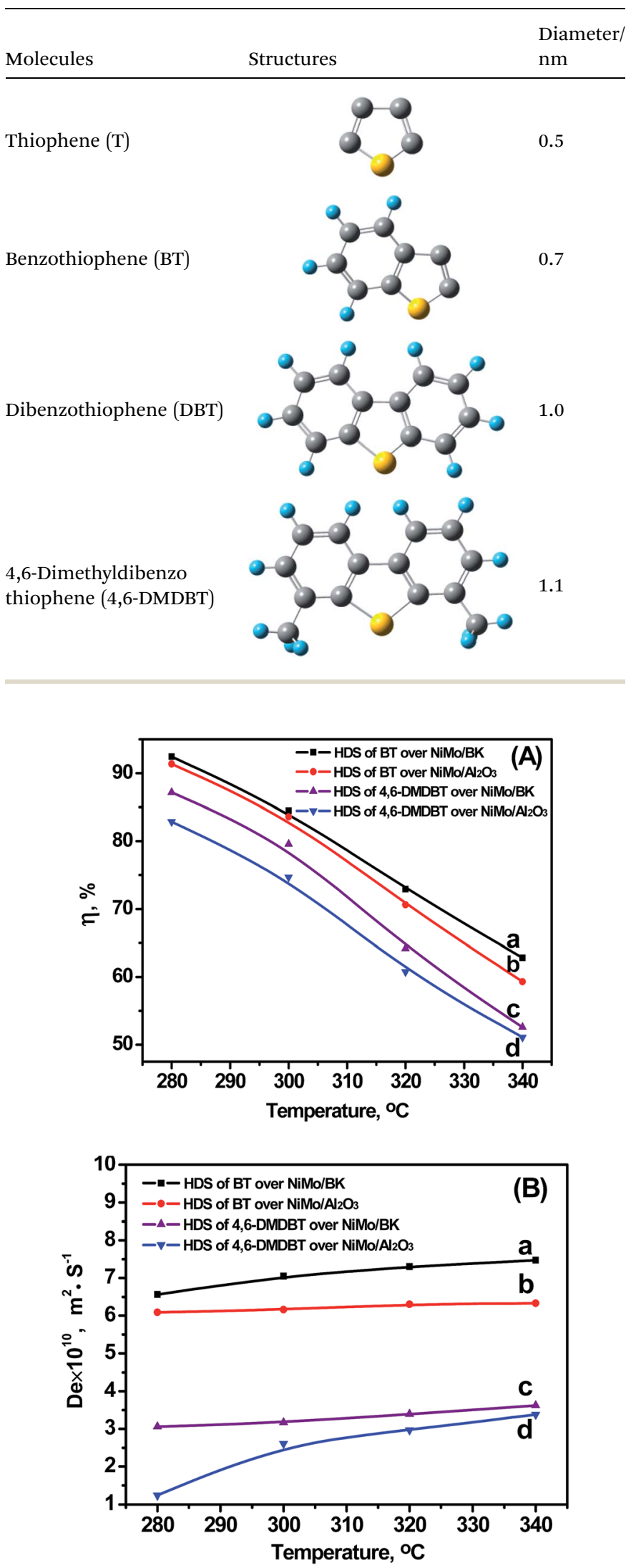

Fig. 6 Relationships between temperature and $\eta(\mathrm{A})$ and $D_{\mathrm{e}}$ (B). (a) HDS of BT over NiMo/BK; (b) HDS of BT over $\mathrm{NiMo} / \mathrm{Al}_{2} \mathrm{O}_{3}$; (c) HDS of 4,6-DMDBT over NiMo/BK; (d) HDS of 4,6-DMDBT over $\mathrm{NiMo} / \mathrm{Al}_{2} \mathrm{O}_{3}$.
$20 \mathrm{~h}^{-1}$, and $600 \mathrm{v} / \mathrm{v}, \eta$ and $D_{\mathrm{e}}$ were obtained as shown in Fig. 9. As the molecular sizes increases, the $\eta$ show an apparent decline tendency with the mode size increasing, while $D_{\mathrm{e}}$ decreased dramatically, indicating that the diffusion resistance becomes significant with the increasing of the reactant sizes. Moreover, $\eta$ and $D_{\mathrm{e}}$ over NiMo/BK are higher than those over $\mathrm{NiMo} / \mathrm{Al}_{2} \mathrm{O}_{3}$ when comparing all of these four sulphur compounds, confirming that the $\mathrm{NiMo} / \mathrm{BK}$ catalyst possesses superior diffusion ability than the traditional $\mathrm{NiMo} / \mathrm{Al}_{2} \mathrm{O}_{3}$ catalyst due to its well-ordered channels.

\subsection{Restrictive factor $F(\lambda)$}

As mentioned above, the diffusion processes of different kinds of sulfide model molecules are affected by various operation conditions, including temperature, pressure, $\mathrm{H}_{2} / \mathrm{Oil}$ ratio, and molecular size. Based on the above HDS results, the reactant size and catalyst pore diameter are two significant critical factors for effective diffusivity.

For the purpose to obtain the relationship between effective diffusivity and the ratio of molecule size to pore size $(\lambda)$, lots of restrictive diffusion processes have been researched. ${ }^{29,30}$ Thus, an empirical formula was proposed and widely used as shown below. $^{31}$
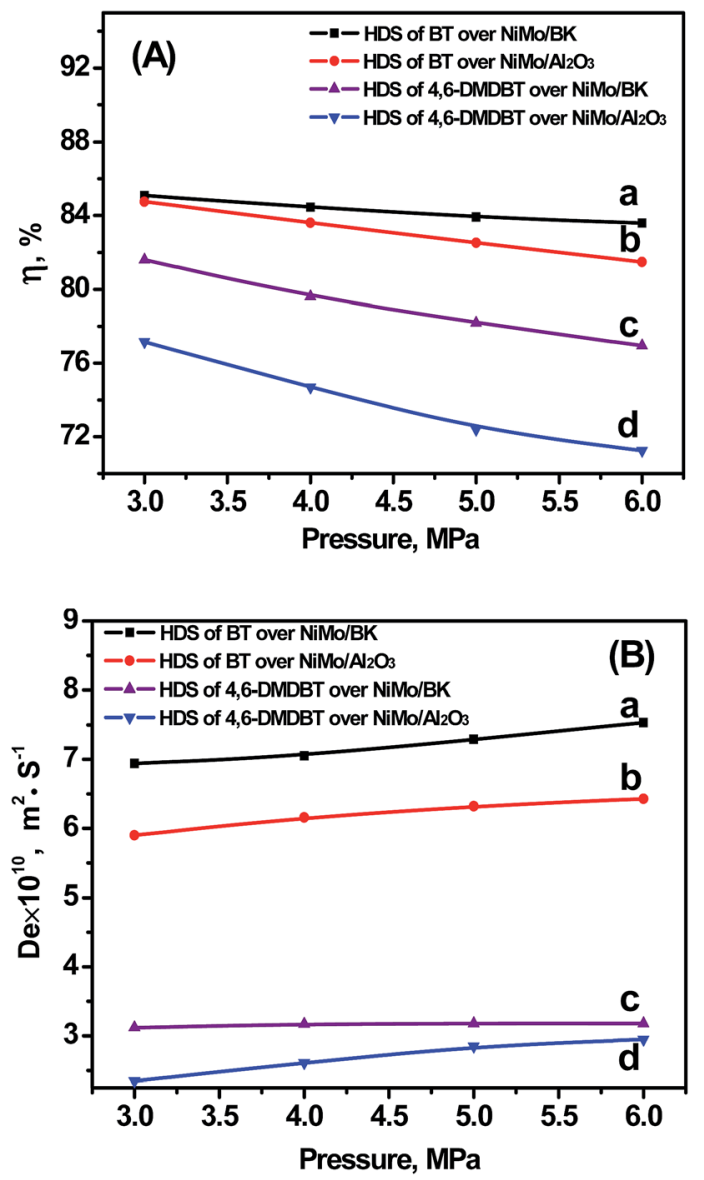

Fig. 7 Relationships between pressure and $\eta(\mathrm{A})$ and $D_{\mathrm{e}}$ (B). (a) HDS of BT over NiMo/BK; (b) HDS of BT over $\mathrm{NiMo} / \mathrm{Al}_{2} \mathrm{O}_{3}$; (c) $\mathrm{HDS}$ of 4,6DMDBT over NiMo/BK; (d) HDS of 4,6-DMDBT over $\mathrm{NiMo} / \mathrm{Al}_{2} \mathrm{O}_{3}$. 

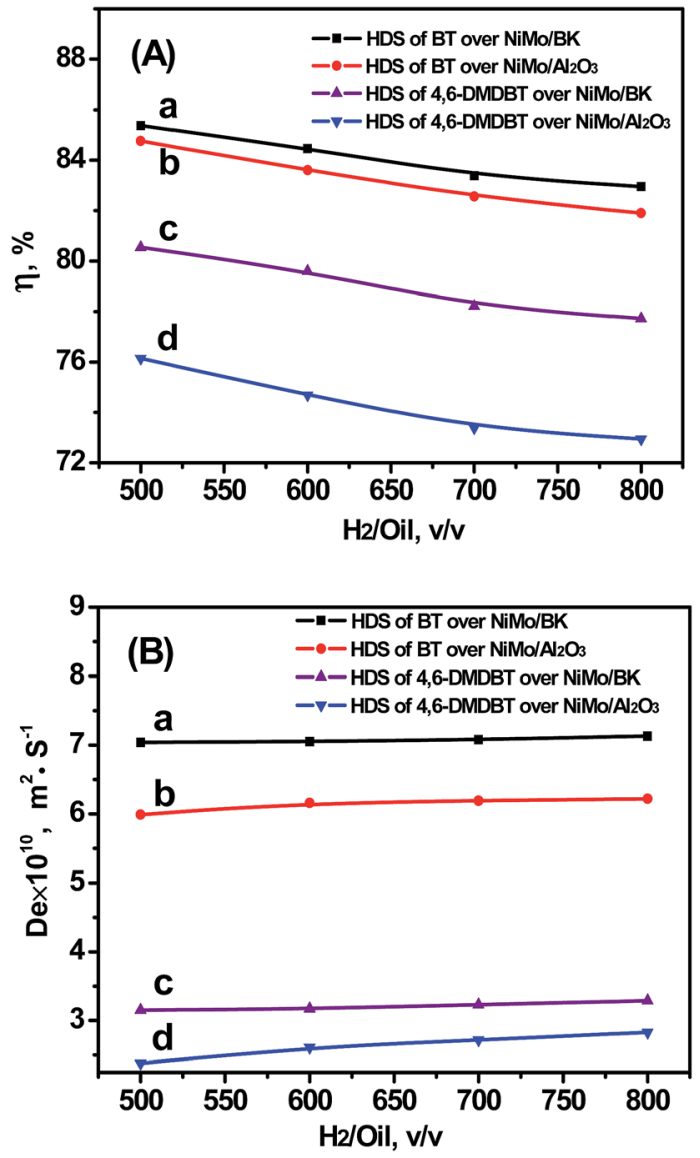

Fig. 8 Relationships between $\mathrm{H}_{2} / \mathrm{Oil}$ and $\eta(\mathrm{A})$ and $D_{\mathrm{e}}$ (B). (a) HDS of BT over NiMo/BK; (b) HDS of BT over $\mathrm{NiMO}_{\mathrm{Al}} \mathrm{O}_{3}$; (c) HDS of 4,6-DMDBT over NiMo/BK; (d) HDS of 4,6-DMDBT over $\mathrm{NiMo} / \mathrm{Al}_{2} \mathrm{O}_{3}$

$$
F(\lambda)=\frac{D_{\mathrm{e}} \tau}{D_{\mathrm{b}} \varepsilon_{\mathrm{p}}}=(1-\lambda)^{m}
$$

where $m$ indicates the hindered magnitude of diffusion, $D_{\mathrm{e}}$ can be calculated as mentioned before. $\varepsilon_{\mathrm{p}}$ is porosity of catalyst, the $\lambda$ and $\varepsilon_{\mathrm{p}}$ are calculated according to the reactant and catalyst properties. $\tau$ represents tortuosity factor of catalyst, however, $\tau$ is not easily measured. As such, the term $\varepsilon_{\mathrm{p}} / \tau$ is viewed as a whole. The bulk diffusivity $\left(D_{\mathrm{b}}\right)$ is calculated from the StokesEinstein equation as shown below ${ }^{32}$ :

$$
D_{\mathrm{b}}=\frac{K T}{6 \pi \mu r}
$$

where $K$ means the Boltzman constant $\left(1.38 \times 10^{23} \mathrm{~J} \mathrm{~K}^{-1}\right), \mu$ is solvent viscosity (Pa s). Pro/II software was used to calculate the $\mu$ value under the reaction condition. Then substituting these values into the above equation, $D_{\mathrm{b}}$ was deduced.

Based on the obtained $D_{\mathrm{e}}$, a logarithmic figure of $D_{\mathrm{e}} / D_{\mathrm{b}}$ versus $1-\lambda$ was plotted (Fig. 10). In addition, the linear fitting curves were given for $\mathrm{NiMo} / \mathrm{BK}$ and $\mathrm{NiMo} / \mathrm{Al}_{2} \mathrm{O}_{3}$ catalysts using Origin 7.0 software. Based on the fitted regression line, the mathematical relationship for the restrictive diffusion is obtained by the equations:
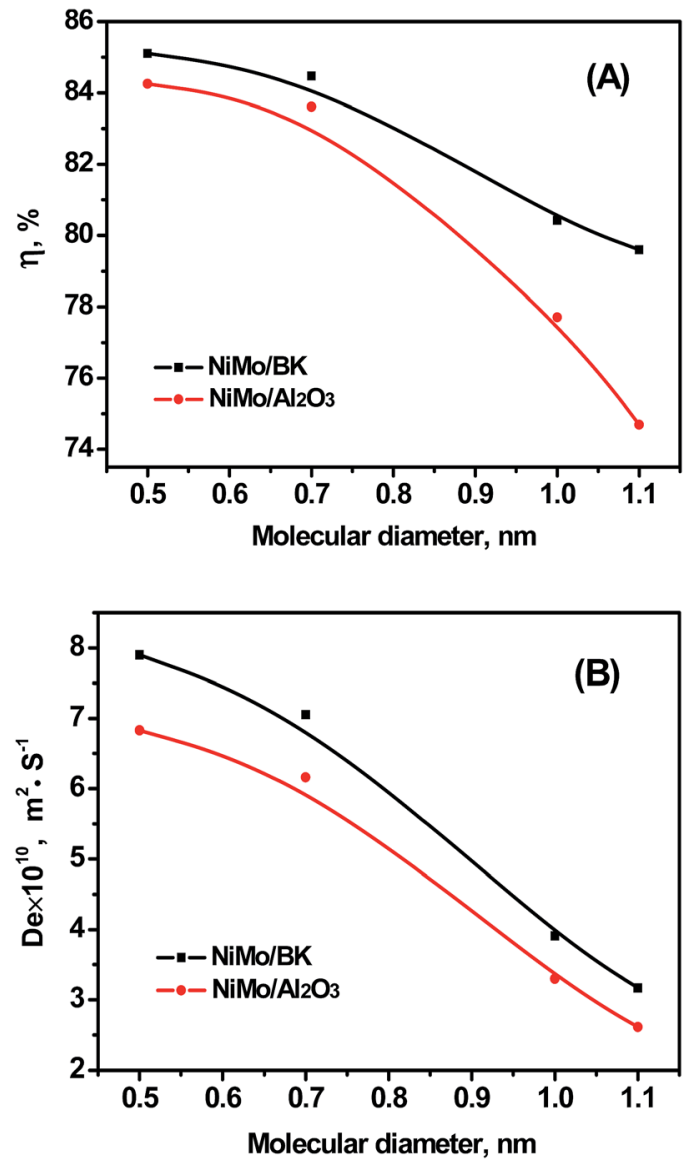

Fig. 9 Relationships between the molecular diameter and $\eta(\mathrm{A})$ and $D_{\mathrm{e}}(\mathrm{B})$.

For NiMo/BK catalyst:

$$
\frac{D_{\mathrm{e}}}{D_{\mathrm{b}}}=\frac{1}{3.81}(1-\lambda)^{3.15}
$$

For $\mathrm{NiMo} / \mathrm{Al}_{2} \mathrm{O}_{3}$ catalyst:

$$
\frac{D_{\mathrm{e}}}{D_{\mathrm{b}}}=\frac{1}{4.19}(1-\lambda)^{3.69} \text {. }
$$

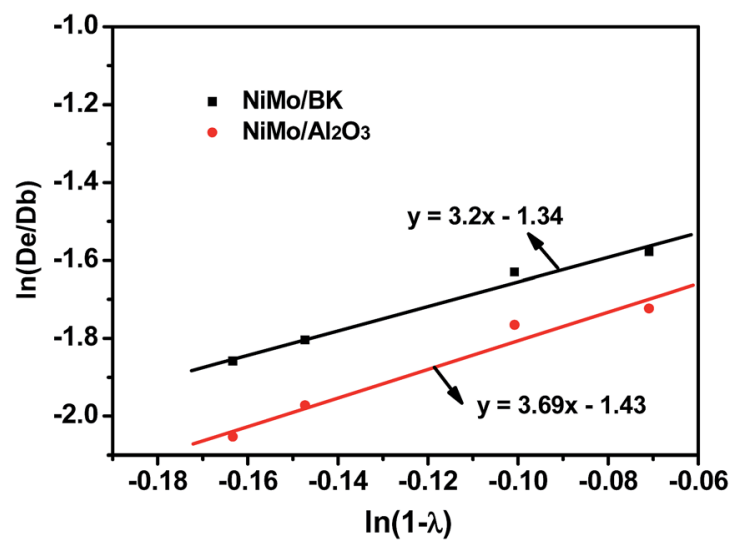

Fig. 10 Restrictive factors as a function of the size/diameter ratio of molecular to catalyst pore. 
Thus, the restrictive factor of $F(\lambda)$ can be described as follows: For NiMo/BK catalyst:

$$
F(\lambda)=(1-\lambda)^{3.15}
$$

For $\mathrm{NiMo} / \mathrm{Al}_{2} \mathrm{O}_{3}$ catalyst:

$$
F(\lambda)=(1-\lambda)^{3.69}
$$

The values of $m$ for the HDS reaction are 3.15 and 3.67 for $\mathrm{NiMo} / \mathrm{BK}$ and $\mathrm{NiMo} / \mathrm{Al}_{2} \mathrm{O}_{3}$ catalysts, respectively, which indicates that the diffusion restriction effect over $\mathrm{NiMo} / \mathrm{BK}$ is smaller than that over $\mathrm{NiMo} / \mathrm{Al}_{2} \mathrm{O}_{3}$ catalyst.

\section{Conclusions}

BK composite micro-mesoporous material with cubic $I a \overline{3} d$ mesoporous structure was synthesized. The synthesized BK material exhibits the similar mesoporous structure as KIT-6, which possesses a bicontinuous mesoporous structure with pore diameter of $\sim 8 \mathrm{~nm}$.

The changing tendencies in $\eta$ and $D_{\mathrm{e}}$ of BT and 4,6-DMDBT molecules over NiMo/BK catalyst in HDS reactions is reported for the first time. The results demonstrated that the reactant restrictive diffusion processes are influenced by reaction conditions and molecule sizes. The reaction temperature exhibits a significant effect on the restrictive diffusion compared with other operating conditions of pressure and $\mathrm{H}_{2}$ / Oil. Furthermore, owning to excellent transfer ability of the wellordered micro-mesoporous NiMo/BK catalyst, the $\eta$ and $D_{\mathrm{e}}$ over $\mathrm{NiMo} / \mathrm{BK}$ catalyst in the HDS of different reactant molecules are all higher than those over $\mathrm{NiMo} / \mathrm{Al}_{2} \mathrm{O}_{3}$ catalyst under the studied reaction conditions due to the excellent transfer property of the well-ordered channels of NiMo/BK catalyst.

The restrictive factors follow the correlations of $F(\lambda)=(1-$ $\lambda)^{3.15}$ for $\mathrm{NiMo} / \mathrm{BK}$ catalyst and $F(\lambda)=(1-\lambda)^{3.67}$ for $\mathrm{NiMo} / \mathrm{Al}_{2} \mathrm{O}_{3}$ catalyst, respectively, which further confirm that the diffusion resistance exists in $\mathrm{NiMo} / \mathrm{BK}$ catalyst is much smaller than that in $\mathrm{NiMo} / \mathrm{Al}_{2} \mathrm{O}_{3}$ catalyst.

\section{Conflicts of interest}

There are no conflicts to declare.

\section{Acknowledgements}

The authors acknowledge the financial supports from the National NSFC (No. 21503152, No. 21276277, No. U1463207), the Opening Project of the Key Laboratory of Green Chemical Process (Wuhan Institute of Technology) (GCP201401), Scientific Research Foundation of Wuhan Institute of Technology (K201640 and K201760), CNOOC Huizhou Refinery Branch (HL00FW2012-0196), and CNPC major project.

\section{References}

1 C. Song and X. Ma, Appl. Catal., B, 2003, 41, 207-238.

2 P. Du, P. Zheng, S. Song, et al., RSC Adv., 2016, 6, 1018-1026.

3 S. A. Ganiyu, S. A. Ali and K. Alhooshani, RSC Adv., 2017, 7, 21943-21952.

4 T. W. Kim, F. Kleitz, B. Paul, et al., J. Am. Chem. Soc., 2005, 127, 7601-7610.

5 H. Zhang, L. Han, A. Duan, et al., RSC Adv., 2017, 7, 2803828047.

6 J. Liu, L. Yu, Z. Zhao, et al., J. Catal., 2012, 285, 134-144.

7 P. Schacht, S. Ramírez and J. Ancheyta, Energy Fuels, 2009, 23, 4860-4865.

8 Y. Luo, V. K. Guda, E. B. Hassan, et al., Energy Convers. Manage., 2016, 112, 319-327.

9 K. Soni, B. S. Rana, A. K. Sinha, et al., Appl. Catal., B, 2009, 90, 55-63.

10 A. Prabhu, L. Kumaresan, M. Palanichamy, et al., Appl. Catal., A, 2009, 360, 59-65.

11 Y. Sun and R. Prins, Angew. Chem., Int. Ed., 2008, 47, 84788481.

12 D. Gao, A. Duan, X. Zhang, et al., Chem. Eng. J., 2015, 270, 176-186.

13 J. Čejka and S. Mintova, Catal. Rev., 2007, 49, 457-509.

14 S. Zeng, J. Blanchard, M. Breysse, et al., Appl. Catal., A, 2006, 298, 88-93.

15 D. Zhang, A. Duan, Z. Zhao, et al., Catal. Today, 2011, 175, 477-484.

16 D. Zhang, A. Duan, Z. Zhao, et al., J. Catal., 2010, 274, 273-286.

17 J. Chen and Z. Ring, Fuel, 2004, 83, 305-313.

18 E. Lecrenay, K. Sakanishi and I. Mochida, Catal. Today, 1997, 39, 13-20.

19 J. Chen, H. Yang and Z. Ring, Catal. Today, 2005, 109, 93-98.

20 T. Kabe, K. Akamatsu, A. Ishihara, et al., Ind. Eng. Chem. Res., 1997, 36, 5146-5152.

21 Y. Sakamoto, T. W. Kim, R. Ryoo, et al., Angew. Chem., Int. Ed., 2004, 43, 5231-5234.

22 V. Umamaheswari, M. Palanichamy and V. Murugesan, J. Catal., 2002, 210, 367-374.

23 P. P. Joaquin, A. M. Johan and A. J. Peter, Appl. Catal., 1987, 31, 35-64.

24 D. E. Mears, Ind. Eng. Chem. Process Des. Dev., 1971, 10, 541-547. 25 J. D. Thoenes and H. Kramers, Chem. Eng. Sci., 1958, 8, 271-276.

26 C. Calais, M. Lacroix, C. Geantet, et al., J. Catal., 1993, 144, 160-174.

27 S. Texier, G. Berhault, G. Pérot, et al., J. Catal., 2004, 223, 404-418.

28 Y. Sun and R. Prins, J. Catal., 2009, 267, 193-201.

29 I. A. Kathawalla and J. L. Anderson, Ind. Eng. Chem. Res., 1988, 27, 866-871.

30 M. C. Tsai, Y. W. Chen and C. Li, Ind. Eng. Chem. Res., 1993, 32, 1603-1609.

31 S. Y. Lee, J. D. Seader, C. H. Tsai, et al., Ind. Eng. Chem. Res., 1991, 30, 607-613.

32 K. J. Laidler and J. H. Meiser, Physical Chemistry, Benjamin/ Cummings, Taipei, 1984, pp. 832-833. 